\title{
Optimising prescribing in primary care: an evaluation of financial and clinical parameters
}

\author{
Asal Albayati ${ }^{1}$, David Lu', Liam Sergeant ${ }^{1}$, Nandita Singh $^{1 *}$, Keith Crump ${ }^{2}$, Zaheer-Ud-Din Babar ${ }^{1}$ \\ From 3rd International PPRI Conference 2015: Pharmaceutical Pricing and Reimbursement Policies: Chal- \\ lenges Beyond the Financial Crisis \\ Vienna, Austria. 12-13 October 2015
}

\section{Problem statement}

The research carried out aimed to encourage evidencebased cost-effective pharmaceutical prescribing, reduce medicine related adverse reactions, improve patient quality of life and reduce pharmaceutical wastage. Prescribing data was evaluated and interventions were subsequently developed in an attempt to improve pharmaceutical prescribing by General Practitioners (GPs) across an enrolled population.

\section{Objectives}

(1) To evaluate the effectiveness of interventions being developed to optimise prescribing by GPs, (2) To recognise factors affecting prescribing patterns of medicines targeted by the programme, and (3) To identify other medicines information sources which influence GP prescribing.

Policy targeted(s): Pharmaceutical prescribing of medicines, in particular medicines available funded through the Pharmaceutical Management Agency (PHARMAC) was evaluated to observe trends in prescribing. These funded medicines are generally generics which are highly accessible to populations in which they are necessary.

Stakeholder: ProCare Health NZ is a Primary Health Organisation which was responsible for data collection and recruiting GPs within its District Health Board.

Region covered: New Zealand WPRO, Region number 13.

* Correspondence: nandita.shivani@gmail.com

'Pharmacy Practice, School of Pharmacy Faculty of Medical and Health Sciences, University of Auckland, Private Mail Bag 92019, Auckland, New

Zealand

Full list of author information is available at the end of the article

\section{Method}

Retrospective delay analysis of pharmaceutical data was conducted using Excel to identify potential reductions in expenditure and volume of targeted pharmaceuticals and pharmaceuticals overall. A pilot prospective, crosssectional study investigating the perceptions held by GPs regarding the influence of Optimising Prescribing interventions on their prescribing practices was also carried out. Research was carried out over a two year period (July 2009 to March 2011). An overview of methodology and interventions used is shown in Figure 1.

\section{Results}

Some medicines showed changes in prescribing volume and pharmaceutical expenditure in response to the initiation of the interventions. For example, the prescribing volume of calcium carbonate in ProCare Network Manukau and East Health dropped sharply after the initiation of Optimising Prescribing interventions, which consists of medicines information bulletins and cell focus groups. However, the prescribing volume of calcium carbonate in ProCare Network Auckland declined before the intervention was initiated, implying that there are other sources of influence involved. From the pilot survey, Best Practice Advocacy Centre (BPAC) was cited by GPs as the most influential source of medicines information in their prescribing practice.

\section{Conslusion}

There is evidence, following the changes in pharmaceutical expenditure and prescribing volume in some investigated medicines. These show Optimising Prescribing interventions to be effective in influencing GP prescribing practices. 


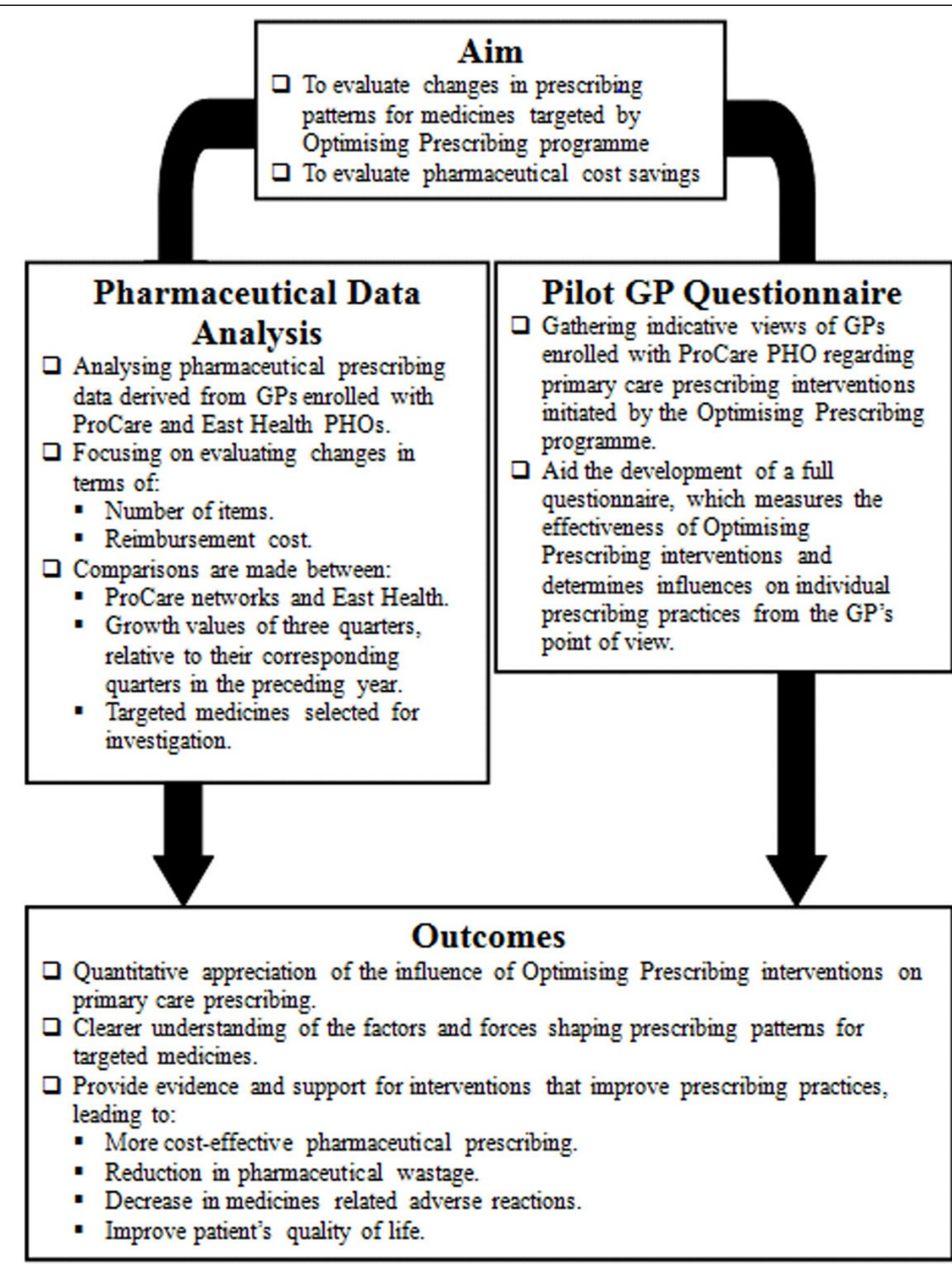

Figure 1 Diagram outlining study methodology

Acknowledgements and funding sources

The research associates would like to extend sincere gratitude and appreciation to everyone who has contributed towards this research. Dr Zaheer-Ud-Din Babar (BPharm, MPharm (Clin Pharm) PhD). Senior lecturer at the School of Pharmacy (University of Auckland) for his guidance and assistance throughout the duration of this research. Keith Crump (MPharm,
PG Dip Pop Health, RegPharmNZ) for enabling the research associates to undertake this research as part of his wider work with ProCare Health Limited. Additionally, the continual support and assistance from ProCare Health is of great significance to this research and the associates sincerely wish to extend their gratitude to all persons involved in ProCare Health Limited. Dr Karen Hvizdos (BPharm PhD Clinical Prescribing Advisor; ProCare 
Health Limited) for supporting the directionality, overall outlook and focus of this research. John Streeter (Data Analyst) ProCare Health Limited for providing pharmaceutical data and for aiding with research results and methodology. Associate Professor Papaarangi Reid, (DipComH Otago, BSc, MBChB, DipObst, FAFPHM), Tumuaki and Head of Department of Māori Health at the Faculty of Medical and Health Sciences, University of Auckland, New Zealand for providing approval to carry out this research and study its implications on the Mãori population. Dale-Lynne Sherman Godinet, ProCare Māori Manager at ProCare Health Limited for her assistance with the ethics approval process. The research associates would also like to extend our gratitude to Counties Manukau District Health Board and Auckland District Health Board for taking part in this research. Finally, the associates would like to extend their sincere gratitude to all the General Practitioners who took part in the pilot questionnaire and for their feedback and responses.

\section{Authors' details}

'Pharmacy Practice, School of Pharmacy Faculty of Medical and Health Sciences, University of Auckland, Private Mail Bag 92019, Auckland, New Zealand. ${ }^{2}$ ProCare Health Ltd, Auckland, 1010, New Zealand.

Published: 5 October 2015

\section{doi:10.1186/2052-3211-8-S1-P18}

Cite this article as: Albayati et al:: Optimising prescribing in primary care: an evaluation of financial and clinical parameters. Journal of Pharmaceutical Policy and Practice 2015 8(Suppl 1):P18.

\section{Submit your next manuscript to BioMed Central and take full advantage of:}

- Convenient online submission

- Thorough peer review

- No space constraints or color figure charges

- Immediate publication on acceptance

- Inclusion in PubMed, CAS, Scopus and Google Scholar

- Research which is freely available for redistribution

Submit your manuscript at www.biomedcentral.com/submit 